\title{
A Pilot Study of 18F-FLT PET/CT in Pediatric Lymphoma
}

\author{
Danny L. Costantini, ${ }^{1,2}$ Reza Vali, ${ }^{1,2}$ Susan McQuattie, ${ }^{2}$ Jeffrey Chan, ${ }^{2}$ Angela Punnett, ${ }^{3}$ \\ Shiela Weitzman, ${ }^{3}$ Amer Shammas, ${ }^{1,2}$ and Martin Charron ${ }^{1,2}$ \\ ${ }^{1}$ Department of Medical Imaging, University of Toronto, $263 \mathrm{McCaul}$ Street, 4th Floor, Toronto, \\ ON, Canada M5T 1 W7 \\ ${ }^{2}$ Department of Diagnostic Imaging, Hospital for Sick Children, 555 University Avenue, Toronto, \\ ON, Canada M5G $1 X 8$ \\ ${ }^{3}$ Department of Pediatrics, Hospital for Sick Children, 555 University Avenue, Toronto, ON, Canada M5G 1X8
}

Correspondence should be addressed to Danny L.Costantini; dan.costantini@utoronto.ca

Received 15 December 2015; Accepted 5 May 2016

Academic Editor: J. M. Mountz

Copyright (C) 2016 Danny L. Costantini et al. This is an open access article distributed under the Creative Commons Attribution License, which permits unrestricted use, distribution, and reproduction in any medium, provided the original work is properly cited.

We performed an observational pilot study of 18F-FLT PET/CT in pediatric lymphoma. Eight patients with equivocal 18F-FDG $\mathrm{PET} / \mathrm{CT}$ underwent imaging with 18F-FLT PET/CT. No immediate adverse reactions to 18F-FLT were observed. Compared to $18 \mathrm{~F}-$ FDG, 18F-FLT uptake was significantly higher in bone marrow and liver (18F-FLT SUV $8.6 \pm 0.6$ and 5.0 \pm 0.3 , versus 18F-FDG SUV $1.9 \pm 0.1$ and $3.4 \pm 0.7$, resp., $p<0.05$ ). In total, 15 lesions were evaluated with average 18 F-FDG and 18 F-FLT SUVs of $2.6 \pm 0.1$ and $2.0 \pm 0.4$, respectively. Nonspecific uptake in reactive lymph nodes and thymus was observed. Future studies to assess the clinical utility of 18F-FLT PET/CT in pediatric lymphoma are planned.

\section{Introduction}

18F-FLT ( $3^{\prime}$-deoxy- $3^{\prime}$-[fluorine-18]-fluorothymidine) is a thymidine analog with uptake that reflects cellular proliferation through the activity of thymidine kinase-1 (TK1), an enzyme that is highly expressed during the synthesis phase of the cell-cycle [1-3]. TK1 phosphorylates 18F-FLT to form negatively charged 18F-FLT-monophosphates which are impermeable to the cell membrane. Since most tumor cells have higher TK1 activity than normal cells, the intracellular trapping of 18F-FLT and accumulation of radioactivity occur [1].

The published literature related to the use of 18F-FLT $\mathrm{PET} / \mathrm{CT}$ in the pediatric population is limited and restricted to studies in pediatric patients with primary brain tumors [4-8]. We therefore sought to evaluate the feasibility of $18 \mathrm{~F}-$ FLT PET/CT in an observational study in a small cohort of pediatric lymphoma patients. Our goals were to assess the normal tissue distribution of $18 \mathrm{~F}-\mathrm{FLT}$ and to provide standardized uptake values (SUVs) of lesions demonstrating equivocal uptake on 18F-FDG PET/CT.

\section{Methods}

2.1. Study Population. This study was approved by our institution's research ethics board (REB number 1000021766). Enrollment was limited to pediatric lymphoma patients with equivocal 18F-FDG PET/CT findings suspicious for malignancy (see "PET/CT Analysis" below for definition of equivocal). Patients/primary caregivers provided written informed consent. 18F-FLT PET/CT findings were not used to influence clinical management.

2.2. Image Acquisition. 18F-FDG PET/CT was performed as previously described [9]. Subsequent 18F-FLT PET/CT was performed within 1 to 3 days. The administered 18FFLT dose $(5.2 \mathrm{MBq} / \mathrm{kg}$ [0.14 mCi/kg], maximum of $370 \mathrm{MBq}$ [10 $\mathrm{mCi}]$ with an accepted $10-20 \%$ variation) and scanning protocol were the same as those for 18F-FDG PET/CT. Based on recommended doses in a $55.5 \mathrm{~kg}$ adolescent, the estimated effective dose from the additional 18F-FLT PET/CT is approximately $4.3 \mathrm{mSv}(0.43 \mathrm{rem})$ [10]. 
TABLE 1: Patient characteristics as well as index lesion location, tracer uptake, and reference standard outcome.

\begin{tabular}{|c|c|c|c|c|c|c|c|c|}
\hline Patient & $\begin{array}{l}\text { Age, } \\
\text { gender }\end{array}$ & $\begin{array}{l}\text { Diagnosis, } \\
\text { stage }^{\ddagger}\end{array}$ & $\begin{array}{l}\text { Index lesion(s) } \\
\text { location }\end{array}$ & $\begin{array}{l}\text { 18F-FDG } \\
\text { SUV }\end{array}$ & $\begin{array}{l}\text { 18F-FDG } \\
\text { liver SUV }\end{array}$ & DS & $\begin{array}{l}\text { 18F-FLT } \\
\text { SUV }\end{array}$ & Reference standard and outcome ${ }^{*}$ \\
\hline \multirow[t]{2}{*}{1} & \multirow[t]{2}{*}{$11, \mathrm{~F}$} & \multirow[t]{2}{*}{ HL, IVA } & $\begin{array}{l}\text { Right subcarinal } \\
\text { LN }\end{array}$ & 2.0 & \multirow[t]{2}{*}{1.2} & 4 & 3.3 & \multirow[t]{2}{*}{ Biopsy, atypical lymphoid hyperplasia } \\
\hline & & & Retrocaval LN & 2.3 & & 4 & 4.1 & \\
\hline 2 & $17, \mathrm{M}$ & HL, IVB & $\begin{array}{c}\text { Anterior } \\
\text { mediastinal mass }\end{array}$ & 2.2 & 2.6 & 3 & 5.0 & Biopsy, thymic tissue \\
\hline $3^{\dagger}$ & $16, \mathrm{~F}$ & HL, IIA & Retroauricular LN & 2.5 & 2.5 & 3 & Nil & $\begin{array}{c}\text { Imaging, resolution on follow-up } 3 \mathrm{mo} \\
\text { 18F-FDG PET/CT }\end{array}$ \\
\hline \multirow{2}{*}{$4^{\dagger}$} & \multirow{2}{*}{$18, \mathrm{~F}$} & \multirow{2}{*}{ HL, IVA } & Prevascular LN & 3.0 & \multirow{2}{*}{2.4} & 4 & Nil & \multirow{2}{*}{$\begin{array}{l}\text { Imaging, resolution on follow-up } 3 \text { mo } \\
\text { 18F-FDG PET/CT }\end{array}$} \\
\hline & & & Prevascular LN & 3.0 & & 4 & Nil & \\
\hline 5 & $17, \mathrm{M}$ & HL, IVA & Lung RUL nodule & 2.2 & 2.3 & 3 & Nil & $\begin{array}{l}\text { Imaging, interval decrease in size on } 3 \mathrm{mo} \\
\text { follow-up chest CT }\end{array}$ \\
\hline \multirow{3}{*}{6} & \multirow{3}{*}{$14, \mathrm{M}$} & \multirow{3}{*}{ HL, IIA } & Jugulodigastric LN & 2.7 & \multirow{3}{*}{2.6} & 3 & 2.2 & \multirow{3}{*}{$\begin{array}{l}\text { Imaging, resolution on follow-up } 3 \text { mo } \\
\text { 18F-FDG PET/CT }\end{array}$} \\
\hline & & & Jugulodigastric LN & 2.4 & & 3 & 2.7 & \\
\hline & & & $\begin{array}{c}\text { Anterior } \\
\text { mediastinal mass }\end{array}$ & 2.6 & & 3 & 1.7 & \\
\hline \multirow{3}{*}{$7^{\dagger}$} & \multirow{3}{*}{$15, \mathrm{M}$} & \multirow{3}{*}{ HL, IIV } & $\begin{array}{l}\text { Posterior cervical } \\
\text { LN }\end{array}$ & 2.5 & & 3 & 1.7 & \multirow{3}{*}{$\begin{array}{l}\text { Imaging, resolution on follow-up } 3 \text { mo } \\
\text { 18F-FDG PET/CT }\end{array}$} \\
\hline & & & Hilar LN & 2.5 & 2.4 & 3 & 1.9 & \\
\hline & & & Hilar LN & 3.4 & & 4 & 1.4 & \\
\hline \multirow{2}{*}{8} & \multirow{2}{*}{$17, \mathrm{M}$} & \multirow{2}{*}{ DLBCL, I } & Jugulodigastric LN & 2.9 & \multirow{2}{*}{2.4} & 4 & 2.8 & \multirow{2}{*}{$\begin{array}{l}\text { Imaging: interval decrease of 18F-FDG uptake } \\
\text { on follow-up } 3 \text { mo 18F-FDG PET/CT (SUV 1.5) }\end{array}$} \\
\hline & & & Submandibular LN & 2.1 & & 3 & 3.4 & \\
\hline
\end{tabular}

${ }^{*}$ Histopathology based on biopsy, when available, or follow-up imaging (i.e., 3-month PET/CT or CT scan) was used as reference standards. HL: Hodgkin lymphoma, DLBCL: diffuse large B-cell lymphoma, SUV: standardized uptake value, LN: lymph node, RUL: right upper lobe, mo: month, and nil: no tracer uptake detected. DS: Deauville score, based on the uptake of $18 \mathrm{~F}-\mathrm{FDG}$ within the index lesion using liver uptake for reference. ${ }^{\dagger}$ Patients who were mid chemotherapy at the time of 18F-FLT PET/CT imaging. ${ }^{\ddagger}$ All patients with HL were initially diagnosed pathologically with the nodular sclerosing subtype.

2.3. PET/CT Analysis. PET/CT was analyzed by two licensed nuclear medicine physicians. Regions of interest (ROIs) were drawn encircling the lesion-of-interest on attenuatedcorrected PET/CT images [9]. For normal tissue distribution, ROIs were drawn around each organ-of-interest to obtain the maximum SUV. Although no clear SUV threshold has been established for 18F-FDG PET/CT for distinguishing benign from malignant uptake, cutoffs in the range of 2.03.5 have been used with high sensitivity and specificity [1114]. We therefore defined "equivocal" as any area of mildly increased 18F-FDG uptake (Deauville score 3 or 4 [15]) with an $S U V \geq 2.0$ but $<3.5$, which could not be characterized by normal physiologic uptake, or factors known to cause falsepositive uptake (e.g., infection/inflammation, brown fat, or thymic rebound) [14]. 18F-FLT PET/CT was similarly visually inspected for any hyperproliferative lesion(s), taking into account the normal physiologic uptake of 18F-FLT that has been described in the adult population $[1,16]$.

2.4. Standard of Reference. PET/CT image findings were compared prospectively in relation to pathology (when tissue sampling was performed within 1 month of $18 \mathrm{~F}-\mathrm{FDG}$ $\mathrm{PET} / \mathrm{CT}$ ), additional cross-sectional imaging, and/or clinical follow-up.

2.5. Statistics. Data are expressed as the mean \pm standard error of the mean. Significance was calculated according to Student's $t$-test; $p<0.05$ was considered significant.

\section{Results}

Between July 2011 and June 2014, twelve patients met enrollment criteria. Consent was obtained in eight patients ( 5 males and 3 females; median age 16.5 years) who subsequently underwent 18F-FLT PET/CT (Table 1). All patients tolerated the imaging procedure well. No immediate adverse reactions were observed. Figure 1 shows the normal tissue distribution of 18F-FDG and 18F-FLT. The highest radiotracer uptake for 18F-FLT was found in bone marrow (using L4/L5 vertebral bodies as surrogate tissues) and liver which was significantly greater compared to 18F-FDG (18F-FLT SUV $8.6 \pm 0.6$ and $5.0 \pm 0.3$, versus 18 F-FDG SUV $1.9 \pm 0.1$ and $3.4 \pm 0.7$, resp., $p<0.05)$. Conversely, 18F-FLT uptake in brain, heart, and gonads was significantly lower compared to $18 \mathrm{~F}-\mathrm{FDG}$ (18FFLT SUV $0.4 \pm 0.1,0.6 \pm 0.03$ and $0.9 \pm 0.1$, versus 18 F-FDG SUV 9.2 $\pm 0.4,2.5 \pm 0.7$ and $2.2 \pm 0.3$, resp., $p<0.05$ ) (Figure 1).

In total, 15 lesions demonstrating equivocal focal uptake (measuring 1-2 cm) on 18F-FDG PET/CT were subsequently evaluated with 18F-FLT PET/CT (Table 1). The average SUV for 18F-FDG and 18F-FLT for all lesions was $2.6 \pm 0.1$ versus $2.0 \pm 0.4$, respectively.

In patients 1 and 2, 18F-FLT uptake by the index lesion was higher compared to 18F-FDG. Both patients completed chemotherapy at the time of 18F-FLT PET/CT. Biopsy of these lesions demonstrated "atypical lymphoid hyperplasia" (patient 1; see Figure 2) and "normal thymic tissue" (patient 2). 


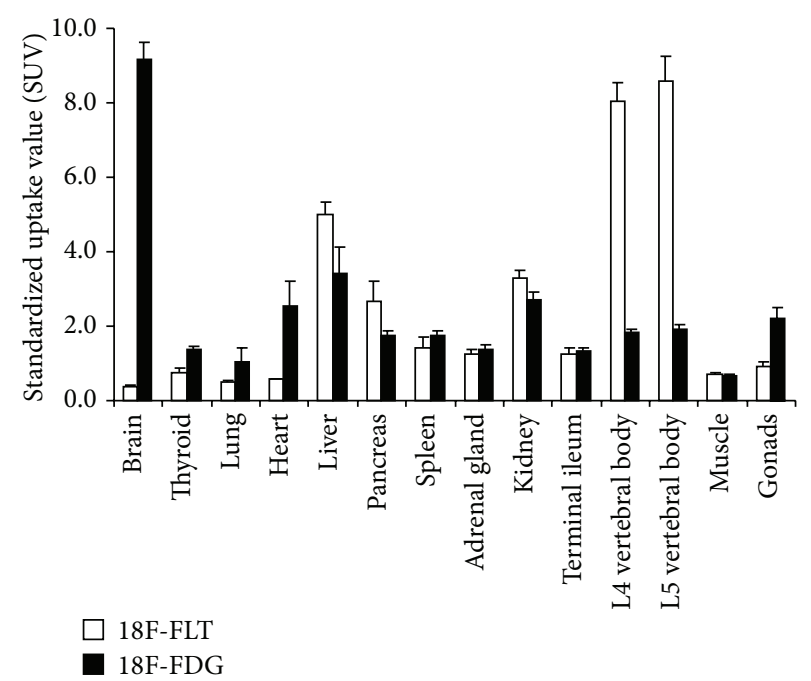

FIGURE 1: Normal tissue distribution of 18F-FDG (black bars) and 18F-FLT (white bars). $y$-axis is measured in standardized uptake value (SUV).

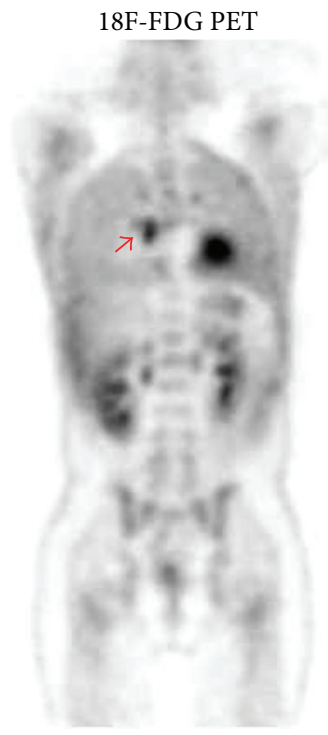

(a)

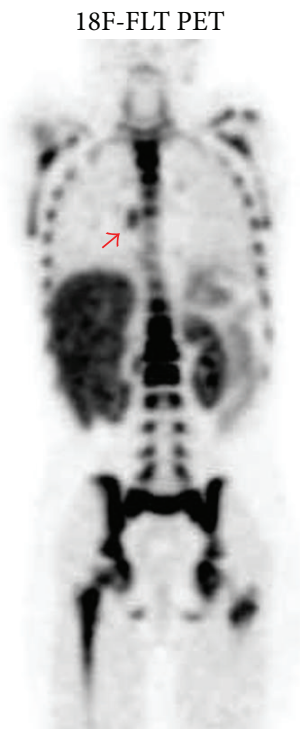

(b)

FIGURE 2: 11-year-old female with stage IVA Hodgkin lymphoma (patient 1) demonstrating increased uptake in a right subcarinal lymph node. Biopsy revealed atypical lymphoid hyperplasia.

In patients 3, 4, and 5, no 18F-FLT uptake in the index lesion was observed and no SUV was calculated (Figure 3). Patients 3 and 4 were mid-treatment at the time of 18FFLT PET/CT. The index lesion demonstrated negligible or stable uptake on a subsequent 3-month follow-up 18F-FDG PET/CT (data not shown). Patient 5 completed chemotherapy at the time of 18F-FLT PET/CT. A follow-up CT demonstrated an interval decrease in the size of the index lesion.

18F-FLT uptake by the index lesions observed in patients 6,7 , and 8 was predominantly lower compared to $18 \mathrm{~F}$-FDG. Patients 6 and 8 completed chemotherapy at the time of 18FFLT PET/CT, whereas patient 7 was mid treatment. Minimal or no 18F-FDG uptake was observed within any of these index lesions on a 3-month follow-up 18F-FDG PET/CT (data not shown).

\section{Discussion}

To our knowledge, the normal tissue distribution of 18FFLT in pediatric patients has not been described. Overall, our data reflects that seen in the adults [17], with decreased 18F-FLT uptake in brain and myocardium and increased uptake in liver and bone marrow relative to 18F-FDG [18]. Increased 18F-FLT uptake in reactive lymph nodes was also 


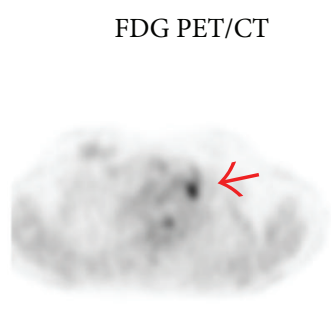

(a)

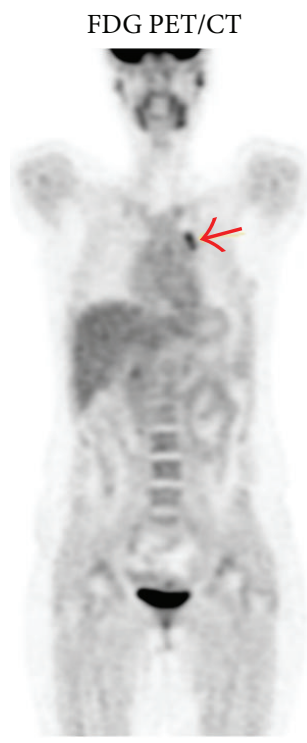

(e)

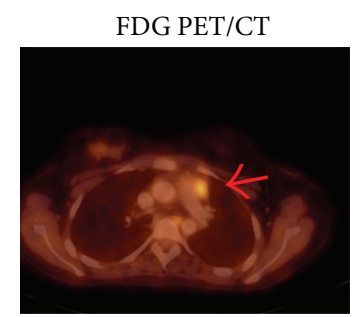

(b)

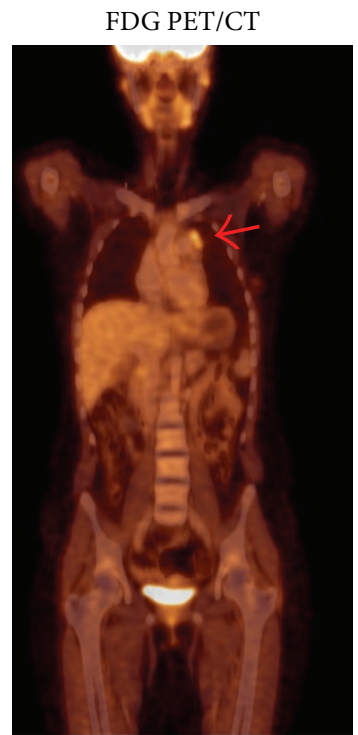

(f)

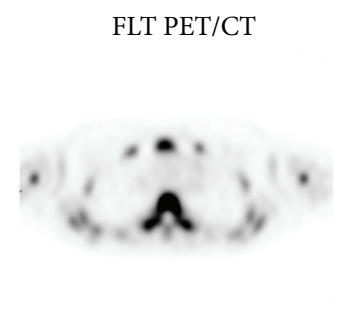

(c)

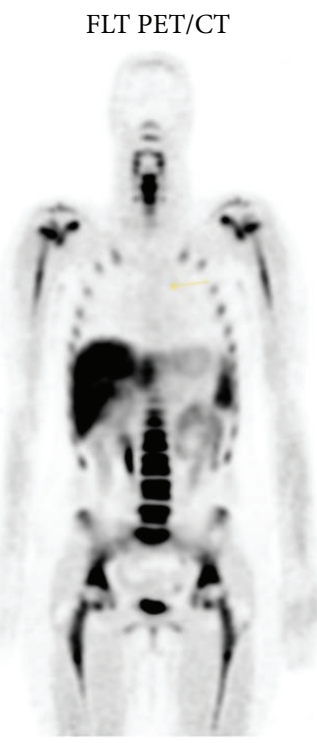

(g)

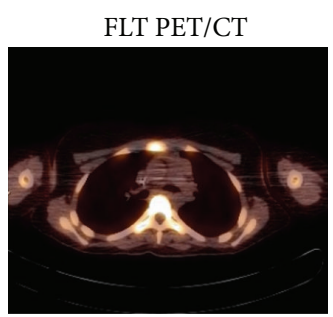

(d)

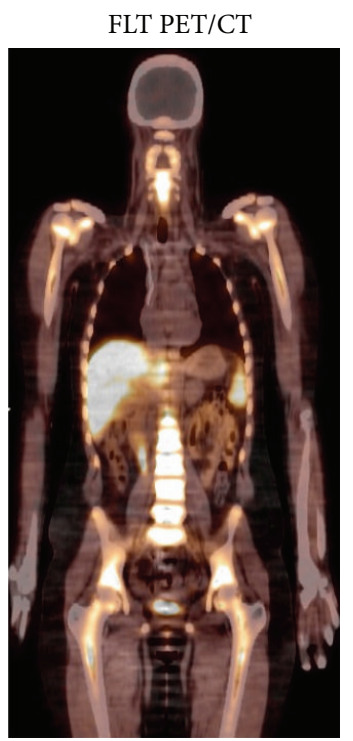

(h)

FIGURE 3: 18-year-old female with stage II Hodgkin lymphoma (patient 4) demonstrating increased uptake in a left prevascular lymph node on FDG PET/CT (a, b and e, f) with 18F-FDG SUV 3.0 and no uptake on 18F-FLT/CT (c, d and g, h). Follow-up 18F-FDG PET/CT performed three (3) months later (not shown) again showed evidence of increased metabolic activity in the prevascular region in the upper mediastinum with SUV of 3.1 and not significantly changed compared to the previous study, and no other focus of increased 18F-FDG uptake to suggest disease progression.

seen mimicking lymphoma recurrence (patient 1). Troost et al. [19] similarly observed elevated 18F-FLT uptake in headand-neck cancer patients due to lymphoid cell proliferation within the germinal centers of reactive lymph nodes. Thymus is another lymphoid organ which similarly caused falsepositive mediastinal 18F-FLT uptake. 18F-FDG uptake in the thymus secondary to postchemotherapy hyperplasia has been well described in pediatric lymphoma PET/CT [14]; however, 18F-FLT thymic uptake is not as well recognized. Awareness of tumor mimics such as those described, as well as knowledge of the normal tissue distribution of 18F-FLT, is critical in the accurate interpretation of 18F-FLT PET/CT.

We found 18F-FLT PET/CT to be useful in equivocal cases of 18F-FDG PET/CT when little or no perceptible 18F-FLT uptake was seen. Patient 5 , for example, was posttherapy at the time of 18F-FLT PET/CT and demonstrated no evidence of recurrent disease on follow-up imaging suggesting that the 18F-FLT PET/CT result represented a true negative finding. Similar findings were obtained in patients 3 and 4; however, the interpretation is confounded by the fact that these patients were mid treatment at the time of 18F-FLT PET/CT. As such the index lesion in these patients could have represented a benign self-limited process versus a malignant lesion with poor FLT avidity and interval treatment response on followup imaging. The value of a positive 18F-FLT PET/CT is unknown since no true positive results were observed. This likely reflects the limited number of patients that were examined and the low likelihood of malignant disease being present in equivocal lesions with relatively low 18F-FDG metabolic activity.

Several studies have attempted to define an optimal 18FFLT SUV for which to separate benign from malignant lesions. Buck et al. [20], for example, concluded that a 18F-FLT SUV cutoff of 3.0 could accurately discriminate between indolent and aggressive lymphomas in adults. If a similar 18F-FLT SUV cutoff is applied in retrospect, it would suggest that the majority of the lesions observed were nonmalignant processes versus (at most) low-grade disease. The lesion in patient 8 had an 18F-FLT SUV > 3.0 and demonstrated complete resolution on follow-up imaging, thus also likely representing a benign etiology. This suggests that a cutoff of 3.0 may be too low of a threshold in our patient series. Indeed, others have suggested higher 18F-FLT SUV cutoffs, for example, in the study by Schöder et al. 
[21] who demonstrated good sensitivity and specificity ( $81 \%$ and $71 \%$, resp.) for distinguishing indolent versus aggressive lymphoma using a 18F-FLT SUV cutoff $>10$.

In conclusion, 18F-FLT PET/CT is well tolerated in pediatric lymphoma patients. 18F-FLT uptake is the highest in liver and bone marrow, whereas minimal uptake in brain and myocardium is seen. Nonspecific uptake can be seen in thymus and reactive lymphadenopathy. Further investigation with a larger number of cases is planned in order to establish meaningful 18F-FLT SUV cutoffs, particularly in the evaluation of pediatric lymphoma.

\section{Abbreviations}

18F-FDG: 2-[Fluorine-18]-fluoro-2-deoxy-D-glucose

18F-FLT: $\quad 3^{\prime}$-Deoxy-3' ${ }^{\prime}$-[fluorine-18]-fluorothymidine

PET/CT: Positron emission tomography/computer tomography

SUV: $\quad$ Standardized uptake value

TK1: $\quad$ Thymidine kinase-1.

\section{Competing Interests}

The authors have nothing to declare.

\section{Acknowledgments}

This work was supported by funds provided by the Garron Family Foundation and the Department of Diagnostic Imaging, Hospital for Sick Children, Toronto, Canada.

\section{References}

[1] J. R. Bading and A. F. Shields, "Imaging of cell proliferation: status and prospects," Journal of Nuclear Medicine, vol. 49, supplement 2, pp. 64S-80S, 2008.

[2] A. F. Shields, "Positron emission tomography measurement of tumor metabolism and growth: its expanding role in oncology," Molecular Imaging and Biology, vol. 8, no. 3, pp. 141-150, 2006.

[3] A. F. Shields, J. R. Grierson, B. M. Dohmen et al., "Imaging proliferation in vivo with [F-18]FLT and positron emission tomography," Nature Medicine, vol. 4, no. 11, pp. 1334-1336, 1998.

[4] S. J. Choi, J. S. Kim, J. H. Kim et al., "[ $\left.{ }^{18} F\right] 3^{\prime}$-deoxy- $3^{\prime}$ fluorothymidine PET for the diagnosis and grading of brain tumors," European Journal of Nuclear Medicine and Molecular Imaging, vol. 32, no. 6, pp. 653-659, 2005.

[5] R. Gilles, W. V. Vogel, C. E. M. Gidding, G. O. R. J. Janssens, T. M. Van Der Vliet, and W. J. G. Oyen, "18F-fluoro-L-thymidinePET for the evaluation of primary brain tumours in children: a report of three cases," Nuclear Medicine Communications, vol. 31, no. 6, pp. 482-487, 2010.

[6] T. Hatakeyama, N. Kawai, Y. Nishiyama et al., "11C-methionine (MET) and 18F-fluorothymidine (FLT) PET in patients with newly diagnosed glioma," European Journal of Nuclear Medicine and Molecular Imaging, vol. 35, no. 11, pp. 2009-2017, 2008.

[7] T. Saga, H. Kawashima, N. Araki et al., "Evaluation of primary brain tumors with FLT-PET: usefulness and limitations," Clinical Nuclear Medicine, vol. 31, no. 12, pp. 774-780, 2006.

[8] M. Tripathi, R. Sharma, M. D’Souza et al., "Comparative evaluation of F-18 FDOPA, F-18 FDG, and F-18 FLT-PET/CT for metabolic imaging of low grade gliomas," Clinical Nuclear Medicine, vol. 34, no. 12, pp. 878-883, 2009.

[9] D. L. Costantini, R. Vali, J. Chan, S. McQuattie, and M. Charron, "Dual-time-point FDG PET/CT for the evaluation of pediatric tumors," American Journal of Roentgenology, vol. 200, no. 2, pp. 408-413, 2013.

[10] H. Vesselle, J. Grierson, L. M. Peterson, M. Muzi, D. A. Mankoff, and K. A. Krohn, "18F-fluorothymidine radiation dosimetry in human PET imaging studies," Journal of Nuclear Medicine, vol. 44, no. 9, pp. 1482-1488, 2003.

[11] D. Delbeke, S. Stroobants, E. de Kerviler, C. Gisselbrecht, M. Meignan, and P. S. Conti, "Expert opinions on positron emission tomography and computed tomography imaging in lymphoma," The Oncologist, vol. 14, supplement 2, pp. 30-40, 2009.

[12] R. Elstrom, L. Guan, G. Baker et al., "Utility of FDG-PET scanning in lymphoma by WHO classification," Blood, vol. 101, no. 10, pp. 3875-3876, 2003.

[13] K. Manohar, B. R. Mittal, S. Raja, A. Bhattacharya, P. Malhotra, and S. Varma, "Comparison of various criteria in interpreting end of therapy F-18 labeled fluorodeoxyglucose positron emission tomography/computed tomography in patients with aggressive non-Hodgkin lymphoma," Leukemia and Lymphoma, vol. 54, no. 4, pp. 714-719, 2013.

[14] A. Shammas, R. Lim, and M. Charron, "Pediatric FDG PET/CT: physiologic uptake, normal variants, and benign conditions," Radiographics, vol. 29, no. 5, pp. 1467-1486, 2009.

[15] A. Gallamini, S. F. Barrington, A. Biggi et al., "The predictive role of interim positron emission tomography for Hodgkin lymphoma treatment outcome is confirmed using the interpretation criteria of the Deauville five-point scale," Haematologica, vol. 99, no. 6, pp. 1107-1113, 2014.

[16] T. Barwick, B. Bencherif, J. M. Mountz, and N. Avril, "Molecular PET and PET/CT imaging of tumour cell proliferation using F-18 fluoro-L-thymidine: a comprehensive evaluation," Nuclear Medicine Communications, vol. 30, no. 12, pp. 908-917, 2009.

[17] M. Charron, Practical Pediatric PET Imaging, Springer, New York, NY, USA, 2006.

[18] A. Salskov, V. S. Tammisetti, J. Grierson, and H. Vesselle, "FLT: measuring tumor cell proliferation in vivo with positron emission tomography and $3^{\prime}$-Deoxy- $3^{\prime}$ - $[18 \mathrm{~F}]$ fluorothymidine," Seminars in Nuclear Medicine, vol. 37, no. 6, pp. 429-439, 2007.

[19] E. G. C. Troost, W. V. Vogel, M. A. W. Merkx et al., " ${ }^{18}$ F-FLT PET does not discriminate between reactive and metastatic lymph nodes in primary head and neck cancer patients," Journal of Nuclear Medicine, vol. 48, no. 5, pp. 726-735, 2007.

[20] A. K. Buck, M. Bommer, S. Stilgenbauer et al., "Molecular imaging of proliferation in malignant lymphoma," Cancer Research, vol. 66, no. 22, pp. 11055-11061, 2006.

[21] H. Schöder, A. Noy, M. Gönen et al., "Intensity of 18fluorodeoxyglucose uptake in positron emission tomography distinguishes between indolent and aggressive non-Hodgkin's lymphoma," Journal of Clinical Oncology, vol. 23, no. 21, pp. 4643-4651, 2005. 


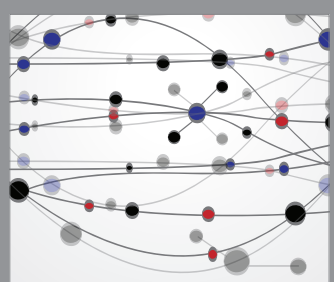

The Scientific World Journal
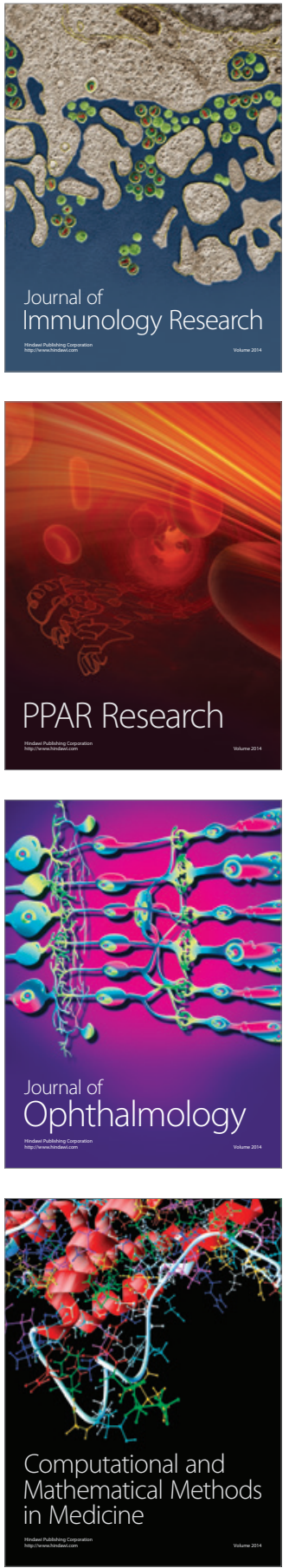

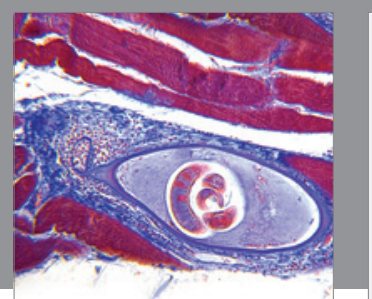

Gastroenterology Research and Practice

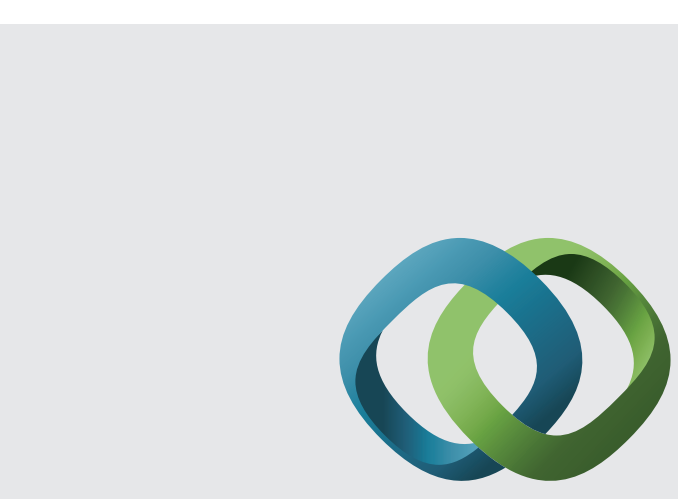

\section{Hindawi}

Submit your manuscripts at

http://www.hindawi.com
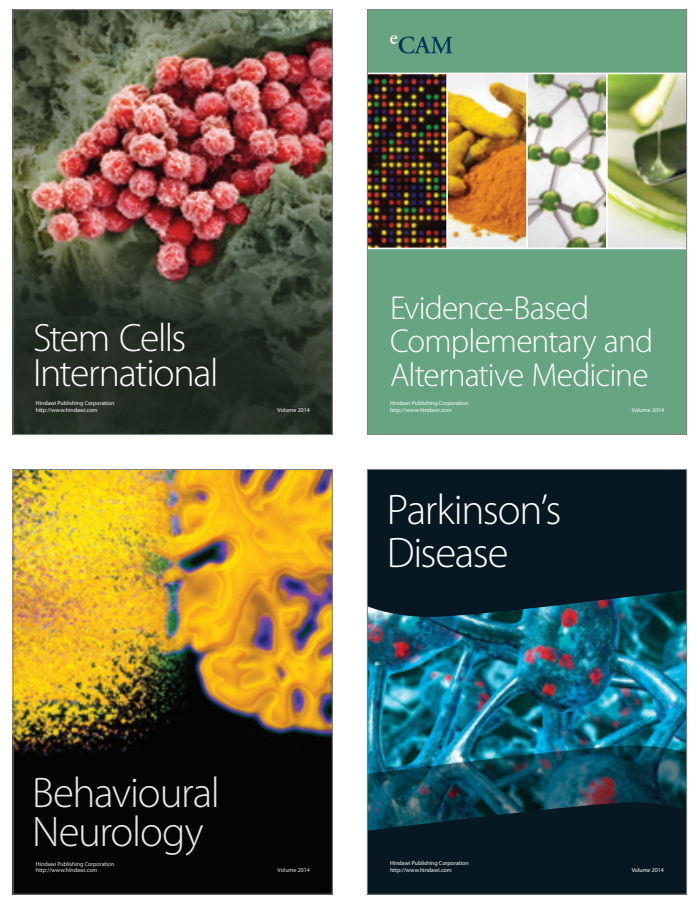
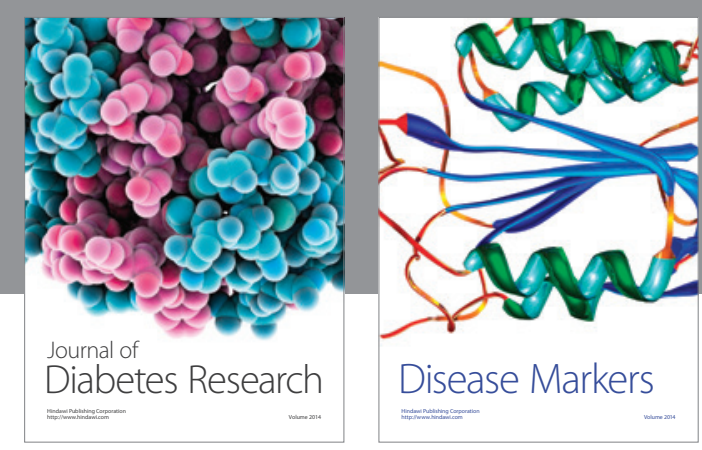

Disease Markers
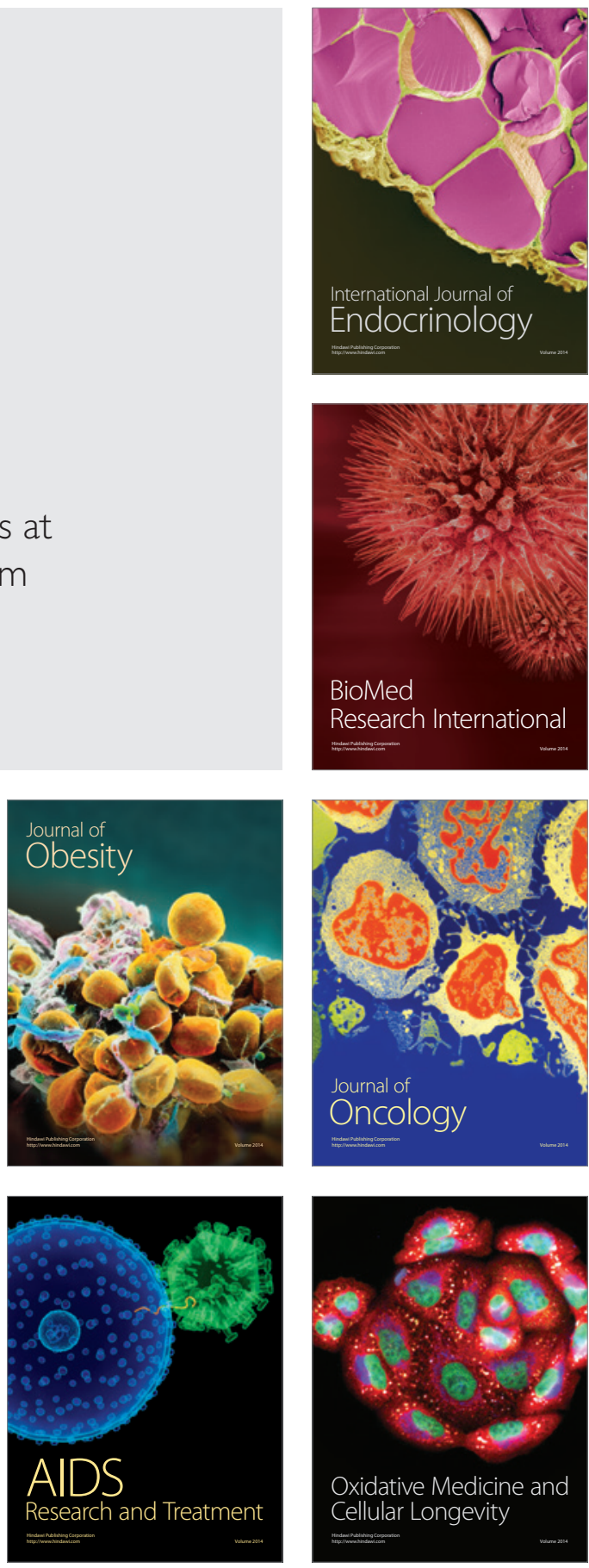